\title{
Article \\ Combined In Vitro and In Vivo Approaches to Propose a Putative Adverse Outcome Pathway for Acute Lung Inflammation Induced by Nanoparticles: A Study on Carbon Dots
}

\author{
Maud Weiss, Jiahui Fan, Mickaël Claudel, Luc Lebeau (), Françoise Pons and Carole Ronzani * \\ Laboratoire de Conception et Application de Molécules Bioactives, Faculté de Pharmacie, UMR 7199, \\ CNRS-Université de Strasbourg, 67400 Illkirch, France; maudweiss@unistra.fr (M.W.); \\ jiahui.fan@etu.unistra.fr (J.F.); mickael.claudel@etu.unistra.fr (M.C.); llebeau@unistra.fr (L.L.); \\ pons@unistra.fr (F.P.) \\ * Correspondence: ronzani@unistra.fr
}

check for

updates

Citation: Weiss, M.; Fan, J.; Claudel, M.; Lebeau, L; Pons, F.; Ronzani, C. Combined In Vitro and In Vivo

Approaches to Propose a Putative Adverse Outcome Pathway for Acute Lung Inflammation Induced by Nanoparticles: A Study on Carbon Dots. Nanomaterials 2021, 11, 180. https://doi.org/10.3390/ nano11010180

Received: 18 December 2020 Accepted: 8 January 2021 Published: 13 January 2021

Publisher's Note: MDPI stays neutral with regard to jurisdictional clai$\mathrm{ms}$ in published maps and institutional affiliations.

Copyright: $\odot 2021$ by the authors. Licensee MDPI, Basel, Switzerland. This article is an open access article distributed under the terms and conditions of the Creative Commons Attribution (CC BY) license (https:// creativecommons.org/licenses/by/ $4.0 /)$.

\begin{abstract}
With the growth of nanotechnologies, concerns raised regarding the potential adverse effects of nanoparticles (NPs), especially on the respiratory tract. Adverse outcome pathways (AOP) have become recently the subject of intensive studies in order to get a better understanding of the mechanisms of NP toxicity, and hence hopefully predict the health risks associated with NP exposure. Herein, we propose a putative AOP for the lung toxicity of NPs using emerging nanomaterials called carbon dots (CDs), and in vivo and in vitro experimental approaches. We first investigated the effect of a single administration of CDs on mouse airways. We showed that CDs induce an acute lung inflammation and identified airway macrophages as target cells of CDs. Then, we studied the cellular responses induced by CDs in an in vitro model of macrophages. We observed that CDs are internalized by these cells (molecular initial event) and induce a series of key events, including loss of lysosomal integrity and mitochondrial disruption (organelle responses), as well as oxidative stress, inflammasome activation, inflammatory cytokine upregulation and macrophage death (cellular responses). All these effects triggering lung inflammation as tissular response may lead to acute lung injury.
\end{abstract}

Keywords: adverse outcome pathway; nanoparticles; carbon dots; nanotoxicology; lung toxicity; lysosome

\section{Introduction}

Since the beginning of the 21st century, engineered nanoparticles (NPs) have been developed for a wide variety of industrial and biomedical applications [1]. Among these $\mathrm{NPs}$, carbon dots (CDs) are the most recent member of the carbon nanomaterial family to be discovered [2]. CDs are spherical and very small-sized $(2-50 \mathrm{~nm})$ nanomaterials that exhibit water solubility, intrinsic fluorescence properties and chemical- and photostability [3]. They can be easily synthesized by top-down or bottom-up approaches. In the top-down method, CDs are produced by breaking down large carbon structures, such as graphite, graphene or carbon nanotubes. In the most popular bottom-up method, they are synthesized using various processes by the carbonization of organic matter (citric acid, glucose, fruit juice, etc.) in the presence of catalysts and/or passivation agents [4]. By varying the synthesis methodology and the nature of the carbon source, catalyst and passivating agent, the intrinsic characteristics of $\mathrm{CDs}$ can be modulated to give them specific physicochemical and optical properties [5,6]. Due to their unique properties, CDs have great potential for applications in various fields, including electronics, catalysis, solar technology or photovoltaics [7]. They are also promising candidate for applications in nanomedicine [8]. Thanks to their intrinsic photoluminescence properties and resistance to photobleaching, 
CDs are especially valuable for optical imaging and stand as a favorable alternative to heavy metal-based quantum dots and organic dyes [9]. Besides, CDs have gradually emerged as novel nano-carriers for drugs such as paclitaxel or doxorubicin [10,11]. Our group and others are also investigating CDs as gene delivery systems $[5,12,13]$. Thanks to the combination of imaging and drug delivery approaches, CDs are increasingly gaining ground as powerful candidates for the development of theranostic applications [14].

Because of their specific properties at the nanoscale, NPs may cause toxic effects at the cell and tissue levels [15]. This is particularly true in the lung, which represents the main route of entry of NPs in the body [16]. Due to their small size, inhaled NPs deposit all throughout the airways, from the bronchi to the alveoli, where they particularly accumulate when compared to larger particles [17]. In alveolar spaces, NPs can be internalized by different cell types, including epithelial cells and macrophages, as it has been reported in mice exposed to carbon nanotubes [18]. If macrophages play a central role in the removal of NPs, their activation after particle uptake may lead to the release of pro-inflammatory cytokines (TNF- $\alpha$, interleukine (IL)-1 $\beta$, IL-6 or IL-8) responsible for an influx of other immune cells such as neutrophils [19]. Besides, activated phagocytes may be an important source of reactive oxygen species (ROS) [20]. As a consequence, several kinds of engineered NPs, such as carbon black, silica or $\mathrm{TiO}_{2} \mathrm{NPs}$ or carbon nanotubes, have been reported to induce acute lung inflammation in animal models [21]. Hence, developing engineered NPs for industrial or biomedical applications requires assessing their safety, especially in the lung.

A key role of nanotoxicology is to understand NP toxicity mechanisms in order to predict the associated health risks [22]. In response to the challenge, and as it is not possible to experimentally test each NP, the identification of adverse outcome pathways (AOPs) has been recently proposed [23]. An AOP is a framework which gathers the existing knowledge on the links between molecular initiating events (MIEs) and adverse outcomes (AOs) induced by a xenobiotic by describing the sequential chain of measurable key events (KEs) at different levels of biological organization that are required to produce a toxic response [24]. To date, more than 200 AOPs are under development, mainly on chemical compounds, and less than about fifty AOPs have been endorsed by the Organization for Economic Cooperation and Development (OECD) [25]. In the lung toxicology field, the AOP for lung fibrosis in response to chemicals (AOP 173) is currently the most advanced (https://aopwiki.org/aops/173), and it is suggested that this AOP would be applicable to NPs [26]. Indeed, some studies conducted on carbon nanotubes showed that mechanisms of carbon nanotube-induced lung fibrosis are common to those described in AOP $173[27,28]$. Other AOPs being currently developed in the field of inhalation toxicology, such as AOP for acute lung toxicity, lung emphysema or lung cancer, are potentially relevant for nanomaterials. But, contrary to chemicals whose MIEs are often well defined (ligand-receptor binding or protein modification), the MIEs and KEs involved in the toxicity cascade evoked by NPs are not yet fully understood [23]. Thus, developing more AOPs specifically related to lung toxicity induced by NPs is essential.

In this context, we combined in vivo and in vitro experimental approaches to propose an AOP for the lung toxicity of CDs. CDs are often described as biocompatible, but some studies recently pointed out a possible toxicity of these nanomaterials [29-31]. In fact, the extreme diversity of the physicochemical characteristics of CDs complicates their safety evaluation. Thus, our team recently explored the impact of the physicochemical characteristics of CDs on their toxicity using a library of 35 CDs with various chemical composition, size, charge and surface chemistry [32]. Among several factors, our data highlighted that surface chemistry and charge strongly impact the toxicity of CDs. In particular, polyamine surface-passivated cationic CDs, which are one type of CDs developed for gene delivery applications, have been shown to be cytotoxic to macrophages. In line with our data, poly(ethyleneimine) (PEI)-based CDs were reported to be cytotoxic towards fibroblasts [29], or kidney and liver cells [30]. Furthermore, CDs passivated with ethylenediamine caused injury and inflammation in the lung of mice after a single inhalation exposure [31]. 
It is therefore important to understand how these NPs exert their toxicity, and how it is possible to overcome it, in order to fully exploit their therapeutic potential. Indeed, the use of CDs as nano-carriers remains a great opportunity, in particular in the fields of theranostic and gene delivery, as CDs are less toxic than, e.g., the standard delivery reagent used for DNA transfection, namely bPEI25k [13]. Production of ROS [29,33], inflammation [34] or activation of the autophagy process $[33,35]$ have been proposed as CD toxicity mechanisms. Recently, our group also reported on the implication of the lysosome in the cytotoxicity of PEI-based CDs [36]. However, to our knowledge, integration of information about CD-induced toxicological events at the cellular and organ levels has not been investigated in the literature yet. In the present study, we first investigated the toxicological effects induced by polyamine-based cationic CDs in the lung of mice. We showed that these CDs induce lung inflammation and identify airway macrophages as their cell target in the organ. Then, we studied the cellular responses induced by these CDs in an in vitro model of macrophages. We thus observed that CDs are internalized by these cells (MIE) and induce loss of lysosomal integrity, mitochondrial disruption, oxidative stress, and inflammasome activation (KEs) leading to macrophage death and lung inflammation. We thus propose a putative AOP for acute lung injury induced by polyamine-based cationic CDs.

\section{Materials and Methods}

\subsection{Preparation and Characterization of CDs}

The CDs investigated herein were produced by microwave-assisted pyrolysis of organic precursors as reported previously [5,32]. In brief, $125 \mathrm{mg}$ citric acid (Merck, Darmstadt, Germany), $500 \mathrm{mg}$ branched poly(ethyleneimine) with molecular weight $600 \mathrm{Da}$ (bPEI600, Sigma-Aldrich, St. Louis, MO, USA) and $5 \mathrm{~mL} \mathrm{HCl} 0.1 \mathrm{~N}$ were mixed in an Erlenmeyer flask, and heated in a domestic microwave oven at a power regime of $620 \mathrm{~W}$, for $170 \mathrm{~s}$. The residue was then dissolved in $\mathrm{HCl} 0.1 \mathrm{~N}$ and centrifuged $(10,000 \mathrm{rpm}$, $5 \mathrm{~min}$ ). The resulting supernatant was loaded in a dialysis bag (MWCO $3500 \mathrm{Da}$ ) for dialysis against $\mathrm{HCl} 0.1 \mathrm{~N}(24 \mathrm{~h})$ and ultra-pure water $(24 \mathrm{~h})$. The dialyzed preparation was lyophilized to yield a brown hygroscopic powder $(275 \mathrm{mg})$.

The hydrodynamic diameter and size distribution of CDs, expressed as polydispersity index (PdI), were measured by dynamic light scattering (DLS, Zetasizer Nano ZS, Malvern Instruments, Paris, France) and calculated from the number distribution graph. Zeta potential was measured by DLS as well and calculated with the Smoluchowski's equation. All measurements were performed in triplicate on fresh samples $(1.0 \mathrm{mg} / \mathrm{mL}$ in $1.5 \mathrm{mM} \mathrm{NaCl} \mathrm{pH} \mathrm{7.4)} \mathrm{at} 25^{\circ} \mathrm{C}$. The morphology of CDs was observed by transmission electron microscopy (TEM) using a bench top LVEM5 microscope (Delong Instruments, Brno, Czech Republic) operating at $5 \mathrm{kV}$. CD samples $(0.5 \mu \mathrm{L}, 1.0 \mathrm{mg} / \mathrm{mL})$ were deposited on glow-discharged ( $90 \mathrm{~V}$ and $2 \mathrm{~mA}$ for $15 \mathrm{~s}$ ) carbon-coated grids (Cu-300HD, Pacific Grid Tech, San Francisco, CA, USA). After at least $2 \mathrm{~h}$ drying at room temperature, the grids were observed. The average size of the NPs was determined by image analysis using the ImageJ software (v 1.50i, NIH, Bethesda, MD, USA), from a set of 687 particles. Elemental composition of CDs was determined by analyzing carbon, hydrogen and nitrogen content (expressed as mass ratio) on a Vario EL III instrument (Elementar, Langenselbold, Germany). Other elements, including oxygen and chlorine, were not quantified. UV-visible and fluorescence measurements were recorded on CD samples prepared in ultra-pure water $(0.10 \mathrm{mg} / \mathrm{mL})$, with an UviKon XL spectrometer (Bio-Tek Instruments, VT, USA) and a Fluoromax-4 spectrofluorometer (Horiba Scientific, Kyoto, Japan), respectively, using a 1-mL quartz cuvette.

\subsection{Animal Experimentation}

Nine-week-old male BALB/c mice were purchased from Charles River Laboratories (Saint-Germain-sur-1'Arbresle, France). Animals were maintained under controlled environmental conditions with a 12-h/12-h light/dark cycle according to the EU guide for use of laboratory animals. Food and tap water were available ad libitum. The animals were ac- 
climated for 1 week before the initiation of the study. Animal experiments were conducted in compliance with the European legislation (Directive 2010/63/EU). Experimental protocols were approved by the local ethics committee (CREMEAS, agreement number \#4674). Mice were exposed to a single dose of 25,50 or $100 \mu \mathrm{g}$ CDs and CD-induced responses were measured $4 \mathrm{~h}, 24 \mathrm{~h}, 7 \mathrm{~d}, 14 \mathrm{~d}$ or $21 \mathrm{~d}$ later. CD samples ( $25 \mu \mathrm{L}$ prepared in saline) were administered into the lung of animals by intranasal instillation. Administration was carried out under anesthesia with $50 \mathrm{mg} / \mathrm{kg}$ ketamine (Imalgen ${ }^{\circledR}$, Merial, France) and $3.33 \mathrm{mg} / \mathrm{kg}$ xylazine (Rompun ${ }^{\circledR}$, Bayer, France) given i.p. Doses of CDs were set to 25, 50 and $100 \mu \mathrm{g}$ according to our previous studies on carbon nanotubes [18,37]. Control animals received instillation of the same volume of saline alone. The experiment was terminated by i.p. injection of a lethal dose of pentobarbital $(100-150 \mathrm{mg} / \mathrm{kg})$.

\subsection{Lung Inflammation Measurement}

Lung inflammation was assessed on bronchoalveolar lavage fluids (BALFs) and lung tissues from $n=6$ mice. The trachea was cannulated to perform bronchoalveolar lavages. Lungs were lavaged by 6 instillations of $0.5 \mathrm{~mL}$ ice-cold saline supplemented with $2.6 \mathrm{mM}$ ethylendiaminetetraacetic acid (EDTA). BALFs recovered from the two first instillations were centrifuged $\left(200 \mathrm{~g}\right.$ for $5 \mathrm{~min}$ at $4{ }^{\circ} \mathrm{C}$ ), and the resulting supernatant was stored at $-20{ }^{\circ} \mathrm{C}$ until cytokine measurements. Cell pellets recovered from the 6 instillations were resuspended in saline-EDTA and used to determine total and differential cell numbers. Total cell counts were determined using a Neubauer's chamber. Differential cell counts were assessed on cytologic preparations obtained by cytocentrifugation (Cytospin 4, Thermo Scientific, Illkirch-Graffenstaden, France). Slides were stained with Microscopy Hemacolor ${ }^{\circledR}$ (Merck, Darmstadt, Germany) and at least 400 cells were counted on each preparation. Macrophage, neutrophil, eosinophil and lymphocyte numbers were expressed as absolute numbers from total cell counts. Moreover, macrophages containing CDs were observed by optical microscopy. After BALF collection, lungs were perfused with ice-cold phosphate buffer solution (PBS) and fixed in 4\% paraformaldehyde for histology. Fixed lungs were rinsed with PBS, dehydrated and embedded in paraffin using standard procedures. Tissue sections $(5 \mu \mathrm{m})$ were then prepared and stained with hematoxylin and eosin (H\&E) to observe inflammation in lung tissue.

\subsection{Flow Cytometry Analysis of Cells Recovered in BALFs}

Flow cytometry analysis of cells recovered in BALFs was conducted in $\mathrm{n}=3$ mice, according to procedures previously described in the literature [38,39]. After tracheotomy, lungs of mice were lavaged with $5 \mathrm{~mL}$ of PBS-EDTA, the recovered BALFs were centrifuged (5 min, $300 \mathrm{~g}$ ), and the pelleted cells were resuspended in $500 \mu \mathrm{L}$ of PBS-EDTA. Then, BALF cells were stained for 30 min with the following antibodies (all from BioLegend, San Diego, CA, USA): Alexa Fluor700 anti-mouse CD45 (clone 30-F11; $0.27 \mu \mathrm{g} / \mathrm{mL}$ ) to identify leukocytes, and PE anti-mouse GR-1 (clone RB6-8C5; $0.06 \mu \mathrm{g} / \mathrm{mL}$ ) and PE-Cy7 anti-mouse CD11c (clone $\mathrm{N} 418 ; 0.24 \mu \mathrm{g} / \mathrm{mL}$ ) to distinguish macrophages from neutrophils. To prevent non-specific binding of antibodies to Fc receptor, a blocking solution (TruStain $\mathrm{FCX}^{\mathrm{TM}}$, BioLegend, San Diego, CA, USA) was added to the antibody mix. Besides, to assess cell viability, cells were stained with the cell death marker TO-PRO ${ }^{\circledR}-3$ (Invitrogen ${ }^{\mathrm{TM}}$, Thermo Scientific, Illkirch-Graffenstaden, France) at $0.08 \mu \mathrm{M}$ just before the flow cytometry analysis. Living cells were discriminated from dead cells according to their fluorescence intensity collected using an APC (red laser) channel. Cellular mortality was expressed as percent of positive cells. To investigate CD uptake by BALF cells, cell fluorescence was measured using the BV421 (violet laser) channel. CD-positive cells were discriminated from CD-negative cells by intensity of the collected fluorescence. Internalization results were expressed as percent of positive cells. Fluorescence measurements were carried out on a LSRFortessa X $20^{\mathrm{TM}}$ flow cytometer (BD Biosciences, Le Pont de Claix, France) and collected data were analyzed using FlowJo ${ }^{\mathrm{TM}}$ software (v 10.2, Ashland, OR, USA). 


\subsection{Cell Culture}

THP-1 (TIB-202 ${ }^{\mathrm{TM}}$, ATCC) cells were grown in culture flasks at $37{ }^{\circ} \mathrm{C}$ in a $5 \% \mathrm{CO}_{2}$ humidified chamber using RPMI-1640 culture medium containing $2 \mathrm{mM}$ L-glutamine, $0.05 \mathrm{mM}$ 2-mercaptoethanol, $100 \mathrm{UI} / \mathrm{mL}$ penicillin, $100 \mu \mathrm{g} / \mathrm{mL}$ streptomycin, and $10 \%$ heat inactivated fetal bovine serum (all reagents from GIBCO, Thermo Scientific, IllkirchGraffenstaden, France). For experiments, cells were seeded in appropriate culture devices and differentiated into macrophages overnight by adding $10 \mathrm{ng} / \mathrm{mL}$ phorbol 12-myristate 13-acetate (PMA, Sigma-Aldrich, St. Louis, MO, USA) to the culture medium.

\subsection{Assessment of CD Cell Uptake and Internalization Mechanisms by Cultured Cells}

Confocal laser scanning microscopy (CLSM) and fluorescence activated cell sorting (FACS) were used to assess CD uptake by cultured cells. For CLSM experiments, cells were seeded into 8-well IbiTreat $\mu$-Slides (1.5 polymer coverslip, IBIDI ${ }^{\circledR}$, Ibidi GmbH, Gräfelfing, Germany) at a density of $10^{5}$ cells / well, differentiated into macrophages, and incubated with CDs for $4 \mathrm{~h}$. At the end of the incubation time, the cells were carefully washed with culture medium and the DSQ12S fluorescent probe (10 nM in PBS) [40] was added to the samples for $5 \mathrm{~min}$ to label the cell membrane. Then, the intracellular localization of CDs was observed using a Leica SP2 microscope equipped with a $63 \times$ oil immersion objective (NA = 1.2). CDs and the DSQ12S membrane probe were excited with 405 and $635 \mathrm{~nm}$ laser sources, respectively. For FACS, cells were seeded into 24-well plates at a density of $5 \times 10^{5}$ cells/well, differentiated into macrophages, and incubated with CDs for $4 \mathrm{~h}$. After CD exposure, the supernatant was discarded and cells were rinsed twice with PBS and harvested by trypsin treatment. Cell suspensions were then analyzed in the LSRFortessa X $20^{\mathrm{TM}}$ flow cytometer and fluorescence of each sample (20,000 events) was collected using a BV421 (violet laser) channel. CD uptake was quantified by determining changes in the mean of the fluorescence intensity (MFI) of CD-treated cells compared to untreated cells. Results were expressed as the ratio of the MFI of CD-treated cells to the MFI of untreated cells.

FACS was also used for identifying mechanisms of CD internalization by cultured cells. Energy dependent internalization was studied by pre-incubating cells at $4{ }^{\circ} \mathrm{C}$ for $30 \mathrm{~min}$ prior to addition of CDs. For studying implication of other internalization pathways, cells were pre-treated for $30 \mathrm{~min}$ with various pharmacological inhibitors: $25 \mu \mathrm{M}$ cytochalasin D (micropinocytosis and phagocytosis), $25 \mu \mathrm{M}$ chlorpromazine (clathrin-dependent pathway), $50 \mu \mathrm{M}$ nystatin, $2.5 \mu \mathrm{M}$ filipin III or $200 \mu \mathrm{M}$ genistein (caveolae-dependent pathway), or $5 \mathrm{mM}$ methyl- $\beta$-cyclodextrin (lipid rafts pathway). Inhibitors were selected according to the literature [41]. Absence of cytotoxicity of these inhibitors at the chosen concentrations was verified (data not shown). Results were expressed as percent of inhibition of CD uptake.

\subsection{Cell Viability Assay}

Cell viability was assessed by the methyl tetrazolium (MTT) assay. Cells were seeded into 96-well plates at a density of $10^{5}$ cells/well, differentiated into macrophages and incubated with increasing concentrations of CDs $(3-200 \mu \mathrm{g} / \mathrm{mL})$ for $24 \mathrm{~h}$. The culture medium was then removed and stored at $-80{ }^{\circ} \mathrm{C}$ until the cytokine assay, and cells were carefully washed with PBS before the addition of complete culture medium containing MTT $(100 \mu \mathrm{L}$ of a $1.0 \mathrm{mg} / \mathrm{mL}$ solution). After incubation for $1 \mathrm{~h}$, culture medium was removed, and cells were lysed with DMSO. Absorbance of the resulting samples was read at $570 \mathrm{~nm}$ with a correction at $690 \mathrm{~nm}$ using a Multiskan FC reader (Thermo Scientific, Illkirch-Graffenstaden, France). Cell viability was expressed as the percentage of the absorbance of CD-treated cells relative to the absorbance of untreated cells.

\subsection{Lysosomal Membrane Integrity Assay}

Neutral red (NR) assay was used to assess lysosomal membrane integrity. Cells were seeded into 96-well culture plates at a density of $10^{5}$ cells/well, differentiated into macrophages, 
and incubated with increasing concentrations of CDs for $24 \mathrm{~h}$. At the end of the incubation period, culture medium was removed and cells were carefully washed with PBS. Complete culture medium containing NR $(200 \mu \mathrm{L}$ of a $100 \mu \mathrm{g} / \mathrm{mL}$ solution $)$ was added to the cells for dye incorporation into intact lysosomes. After a 3-h incubation period, culture medium was removed and cells were lysed with $1 \%$ acetic acid solution containing $50 \%$ ethanol to release the incorporated dye. Absorbance of the resulting samples was read at $570 \mathrm{~nm}$ with a correction at $690 \mathrm{~nm}$. Results were expressed as the percentage of the absorbance of treated cells relative to the absorbance of non-exposed control cells.

\subsection{Oxidative Stress Assessment}

Oxidative stress was assessed by measuring changes in reduced glutathione (GSH) cellular levels using the 2,3-naphthalenedialdehyde (NDA) probe. Cells were seeded into 24-well culture plates at a density of $5 \times 10^{5}$ cells/well, differentiated into macrophages and incubated for $4 \mathrm{~h}$ with increasing concentrations of CDs. At the end of the CD exposure, cells were washed with $5 \mathrm{mM}$ EDTA, $40 \mathrm{mM} \mathrm{NaH} \mathrm{PO}_{4}, 110 \mathrm{mM} \mathrm{Na}_{2} \mathrm{HPO}_{4}(\mathrm{pH}$ 7.4), and lysed with $0.1 \%$ Triton $\mathrm{X} 100^{\circledR}$. Then, proteins were denatured and precipitated $(0.1 \mathrm{M}$ hydrochloric acid, 50\% sulfosalicylic acid) before sample centrifugation (10,000 g, $15 \mathrm{~min}$, $4{ }^{\circ} \mathrm{C}$ ). Cell lysates were then incubated with the NDA probe for $25 \mathrm{~min}$ at $4{ }^{\circ} \mathrm{C}$, before fluorescence measurement $\left(\lambda_{\mathrm{ex}}=485 \mathrm{~nm} ; \lambda_{\mathrm{em}}=528 \mathrm{~nm}\right)$ using a Varioskan multimode reader (Thermo Scientific, Illkirch-Graffenstaden, France). A calibration curve was used to calculate the amount of reduced GSH in the samples. This amount was then expressed in nmol of GSH per mg of protein. To do so, protein concentration in samples was determined using the bicinchoninic assay (BCA, Sigma-Aldrich, St. Louis, MO, USA) according to the manufacturer's instructions.

\subsection{Mitochondrial Membrane Potential Assay}

Mitochondrial membrane potential was assayed using the JC-10 fluorescent probe (Sigma-Aldrich, St. Louis, MO, USA) according to the manufacturer's instructions. Cells were seeded into 96-well culture plates at a density of $10^{5}$ cells / well, differentiated into macrophages, and incubated with increasing concentrations of CDs for $4 \mathrm{~h}$. After the CD treatment, the cell culture supernatant was removed and the JC-10 probe $(100 \mu \mathrm{L})$ was added to the cells for $1 \mathrm{~h}$. Then, fluorescence of the samples was measured (functional mitochondria: $\lambda_{\mathrm{ex}}=540 \mathrm{~nm}, \lambda_{\mathrm{em}}=590 \mathrm{~nm}$; non-functional mitochondria: $\lambda_{\mathrm{ex}}=490 \mathrm{~nm}$, $\left.\lambda_{\mathrm{em}}=525 \mathrm{~nm}\right)$. The ratio of fluorescence intensity at $525 \mathrm{~nm}$ to fluorescence intensity at $590 \mathrm{~nm}$ was calculated for each sample. Data were expressed as the fold change of CD-exposed cells relative to the non-exposed control cells.

\subsection{Cytokine Assay}

IL-6, IL-8, IL-1 $\beta$, KC and MCP-1 were measured in BALFs or in cell culture supernatants by ELISA according to the manufacturer's instructions (R\&D Systems, Lille, France).

\subsection{Statistical Analysis}

Experiments were carried out on $n=3-9$ biological replicates (in vitro experiments) or on $n=3-6$ mice (in vivo experiments). Data are presented as mean \pm SEM. Statistical differences between groups were determined by Student $t$-test or analysis of variance (ANOVA) followed by Dunnett's test, using the GraphPad Prism software (v 6.0, San Diego, CA, USA). Data were considered as significantly different when $p<0.05$.

\section{Results and Discussion}

\subsection{Characterization of CDs}

The mean hydrodynamic diameter of CDs was $10.1 \pm 0.4 \mathrm{~nm}$ with a polydispersity index of $0.240 \pm 0.061$ (Table 1). The zeta potential $(\zeta)$ of the CDs was $+23.9 \pm 2.0 \mathrm{mV}$, indicating a positive surface charge of the NPs and revealing the presence of grafted poly(ethyleneimine) residues at the surface. CDs appeared as rounded particles on TEM 
images (Figure 1a), with a mean diameter of ca. $39.5 \mathrm{~nm}$. The discrepancy between the size as determined by DLS and TEM might result from some aggregation of the NPs under capillary forces upon deposition and drying of the sample on the TEM grid. Nitrogen, carbon, and hydrogen contents of CDs were $14.6 \%, 29.0 \%$, and $6.95 \%$, respectively. Concerning the optical properties of the CDs, the UV-vis absorption and fluorescence emission and excitation spectra were recorded (Figure 1b), and revealed a maximum absorption, fluorescence excitation and emission wavelengths at 354, 368 and $462 \mathrm{~nm}$, respectively. These intrinsic photoluminescence properties make it possible to follow CD fate in biological conditions without the addition of a fluorescent marker.

Table 1. Physicochemical characteristics of CDs.

\begin{tabular}{cc}
\hline Characteristics & Data \\
Size & DLS: $10.1 \pm 0.4 \mathrm{~nm}, \mathrm{PdI}=0.240 \pm 0.061$ \\
Surface charge & TEM: $39.5 \mathrm{~nm}$ \\
Chemical composition & Zeta potential: $\zeta=+23.9 \pm 2.0 \mathrm{mV}$ \\
& Nitrogen: $14.6 \%$ \\
Photoluminescence & Carbon: $29.0 \%$ \\
& Hydrogen: $6.95 \%$ \\
& $\lambda_{\text {max }}: 354 \mathrm{~nm}$ \\
& $\lambda_{\text {ex }}: 368 \mathrm{~nm}$ \\
& $\lambda_{\text {em }}: 462 \mathrm{~nm}$ \\
\hline
\end{tabular}

(a)

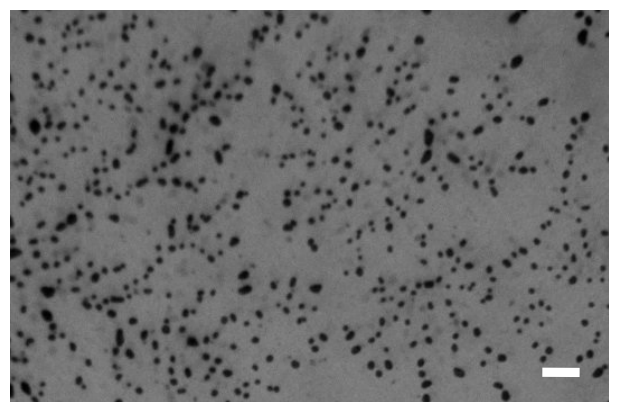

(b)

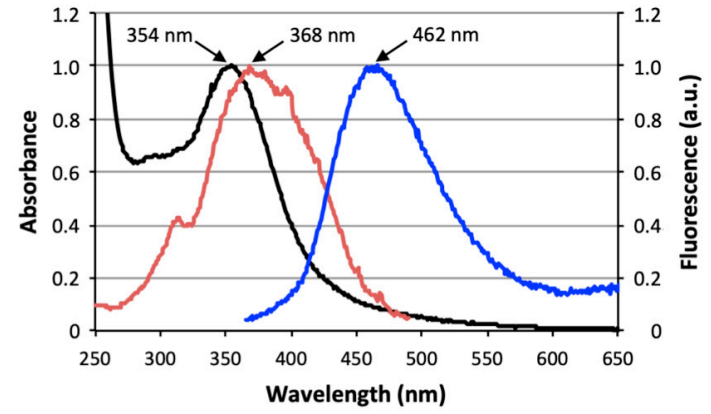

Figure 1. (a) Morphology of the bPEI600-based CDs as observed by TEM (scale bar $=200 \mathrm{~nm}$ ). (b) Optical properties of the CDs: absorption (black), excitation (red), and emission (blue; excitation at $355 \mathrm{~nm}$ ) spectra.

\subsection{Lung Inflammation in Response to CDs}

First, we examined whether the prepared CDs could induce an inflammatory response in the lung of mice. Animals were exposed to saline (control mice) or increasing doses of CDs $(25,50$ or $100 \mu \mathrm{g})$, and BALFs were collected $24 \mathrm{~h}$ later. As shown in Figure 2a, a neutrophil infiltrate was observed in BALFs of mice that received $50(p<0.01)$ or $100 \mu \mathrm{g}$ $(p<0.001)$ of CDs, when compared to the control group. In line with these findings, levels of the pro-inflammatory cytokines IL-6, KC, and MCP-1 were significantly increased in BALFs from mice exposed to $50(p<0.01)$ or $100 \mu \mathrm{g}(p<0.001)$ of CDs (Figure 2b). Histopathology of lung tissue from mice exposed to CDs revealed the presence of peribronchial and perivascular cellular infiltrates, which confirmed the inflammatory response found in BALFs (Figure 2c). Thus, all together, the herein described bPEI600-based CDs evoked a dose-dependent lung inflammation. This toxicological effect occurs in the same dose range as that evoked by other carbonaceous nanomaterials, namely carbon black [42,43] and carbon nanotubes [18]. Furthermore, it is in keeping with the data reported by other groups on ethylenediamine-based CDs [31], confirming that polyamine surface-passivated cationic CDs trigger adverse outcome in the lung. 


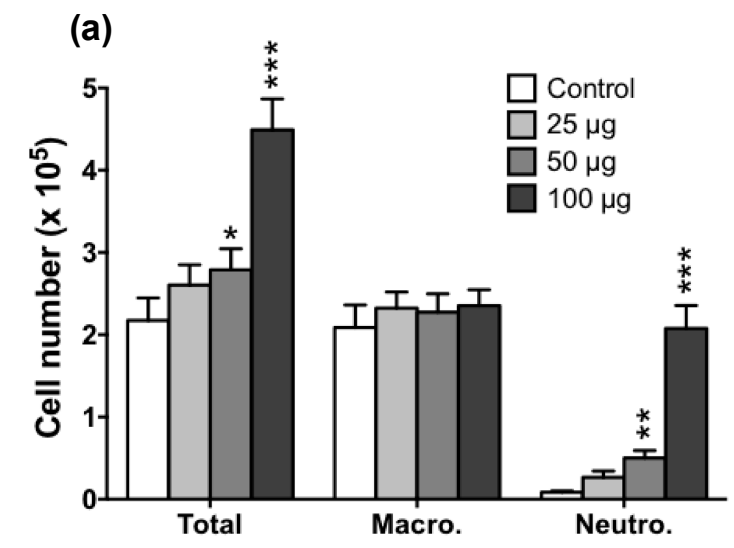

(b)

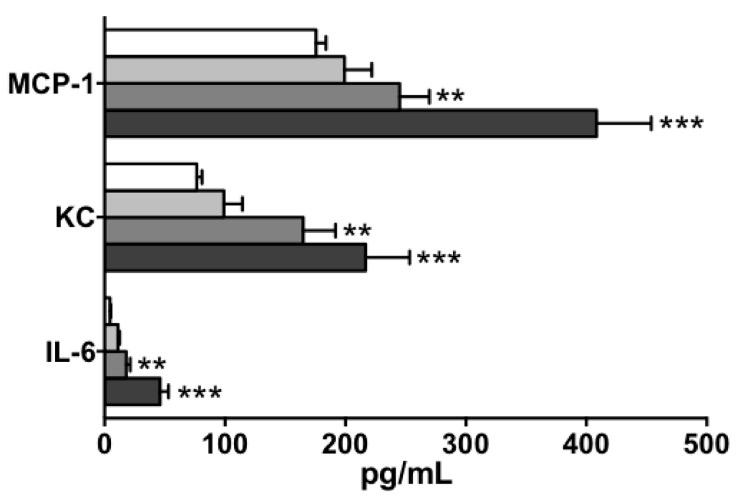

(c)
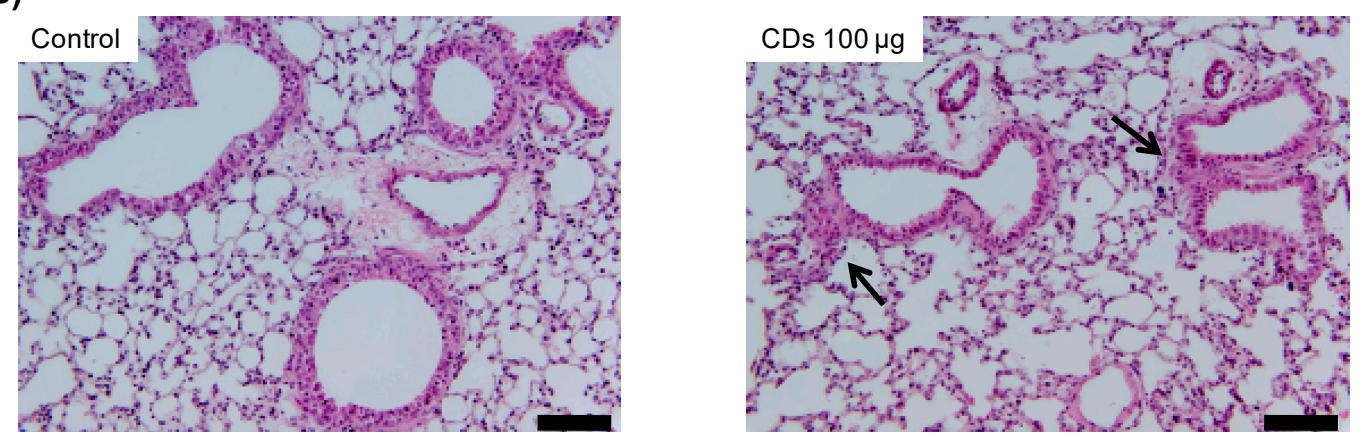

Figure 2. Lung inflammation induced by CDs in mice. Mice received a single administration of 25, 50 or $100 \mu \mathrm{g}$ of CDs, and airway inflammation was assessed $24 \mathrm{~h}$ later. (a) Total and differential cell counts and (b) proinflammatory cytokines in BALFs. Data are means \pm SEM of $\mathrm{n}=6$ mice. Statistical differences when compared to controls were determined by ANOVA followed by the Dunnett's test. ${ }^{*} p<0.05$; ${ }^{* *} p<0.01 ;{ }^{* *} p<0.001$. (c) Histopathology of lung tissues from control mice (left) or mice exposed to $100 \mu \mathrm{g}$ CDs (right). Lung sections were stained with hematoxylin and eosin (scale bar $=50 \mu \mathrm{m}$; black arrow: cell infiltrate).

\subsection{Cell Target in the Airway Lumen}

We then focused on the identification of the cells targeted by the CDs in the airways lumen of mice by analyzing cells recovered in BALFs by FACS. The staining and gating strategy made it possible to measure both the CD cell uptake (Figure 3) and mortality (Figure 4) while discriminating the different cell types. Mice received one administration of CDs $(100 \mu \mathrm{g})$ or saline, and BALFs were collected after $4 \mathrm{~h}, 24 \mathrm{~h}, 7 \mathrm{~d}, 14 \mathrm{~d}$ or $21 \mathrm{~d}$. As shown on Figure $3 \mathrm{a}$ for the 4-h time point, macrophages (CD45+CD11c+GR-1-) and neutrophils $(\mathrm{CD} 45+\mathrm{CD} 11 \mathrm{c}+\mathrm{GR}-1+)$ were the two main cell populations present in BALFs from mice exposed to CDs, which is in agreement with cytological data of Figure 2a. To investigate $\mathrm{CD}$ uptake, the CD-associated fluorescence was measured into these two cell populations. No internalization was measured within neutrophils (data not shown). In contrast, an important CD uptake was observed within macrophages (Figure 3a, panel internalization within macrophages). Examination of BALF cells from mice exposed to CDs by optical microscopy showed CD-loaded macrophages (Figure 3b), which confirmed the FACS data. Regarding the kinetics of CD internalization by macrophages, more than $50 \%$ of cells had internalize CDs as early as $4 \mathrm{~h}$ after instillation of the NPs in the lung of mice, and this internalization increased further at $24 \mathrm{~h}$, with more than $75 \%$ of CD-loaded macrophages (Figure 3c). Presence of CDs into macrophages started to decrease from day 7 after administration, but the NPs were still present at day 21, suggesting that they are not rapidly cleared. 
(a)

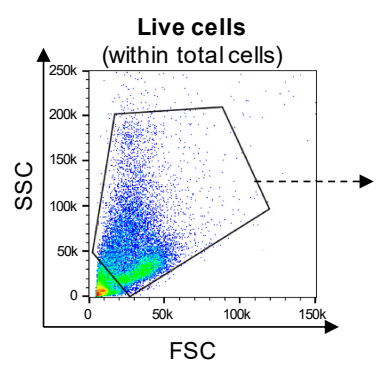

Internalization

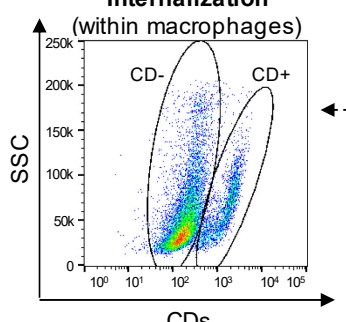

CDs

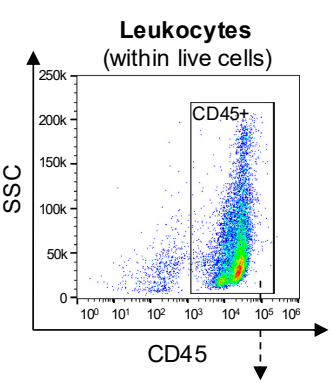

Cell differentiation (within leukocytes)

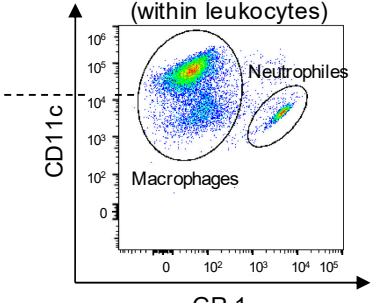

(b)

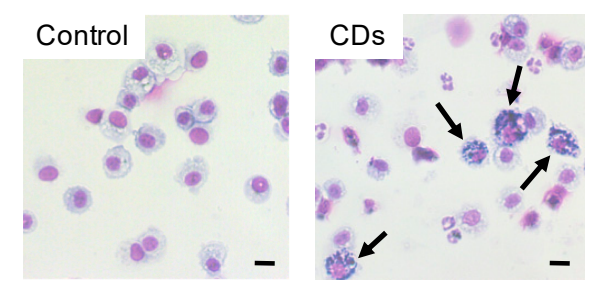

(c)

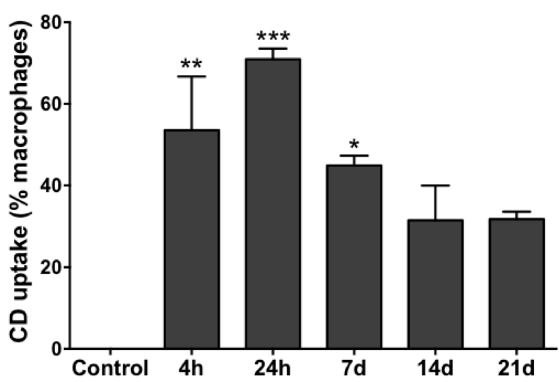

Figure 3. Uptake of CDs by cells of the airway lumen as studied by FACS (a,c) or optical microscopy (b). Mice received one administration of CDs $(100 \mu \mathrm{g})$ or saline, and BALFs were collected 4 h, 24 h, 7 d, $14 \mathrm{~d}$, or $21 \mathrm{~d}$ later. (a) Gating strategy to identify the cell types present in BALFs and to measure CD cell uptake by FACS (data from the 4-h time point). (b) Cells recovered from BALFs of control mice (left) or mice exposed to $100 \mu \mathrm{g}$ CDs at the 4-h time point (right) as observed by optical microscopy. The arrows show macrophages loaded with CDs (scale bar $=10 \mu \mathrm{m})$. (c) Kinetics of internalization of CDs by alveolar macrophages as assessed by FACS. Data are means \pm SEM of $\mathrm{n}=3$ mice. Statistical differences when compared to controls were determined by ANOVA followed by the Dunnett's test. ${ }^{*} p<0.05 ;{ }^{* *} p<0.01 ;{ }^{* *} p<0.001$.

Macrophage mortality induced by CDs was assessed by combined analysis of CDassociated fluorescence (X-axis) and fluorescence of the TO-PRO-3 cell mortality marker (Y-axis) (Figure 4a). Thus, different macrophage populations were discriminated: living macrophages with no CD uptake; living macrophages with CD uptake; dead macrophages without CD uptake; dead macrophages with CD uptake. As shown on Figure 4b, a macrophage mortality of approximately $15 \%$ was found in control mice, which is in agreement with what is generally reported in studies performing FACS on BALFs [38]. In contrast, significant macrophage mortality was observed in BALFs from mice exposed to CDs, since cell death affected almost $50 \%$ of the total macrophage population at $4 \mathrm{~h}$ and $24 \mathrm{~h}$ after exposure to the NPs. Among the dead macrophages, between $20 \%$ and $25 \%$ of the cells contained CDs at $4 \mathrm{~h}$ and $24 \mathrm{~h}$, respectively. These data suggest that CDs can exert a direct toxicity on macrophages after their cell uptake. However, macrophage mortality decreased sharply from 7-d post-exposure and returned to a level comparable to control at $21 \mathrm{~d}$ after CD exposure, suggesting that there is a possible recovery of the alveolar macrophage population from $21 \mathrm{~d}$ after a unique $\mathrm{CD}$ exposure.

Thus, we found that alveolar macrophages are the main cell target of bPEI600-based CDs in the lung. Uptake of NPs by macrophages has been reported for various kinds of nanomaterials $[42,44]$ and is now widely accepted. As alveolar macrophages constitute the first line of defense against foreign materials in the lung [45], NP engulfing by macrophages plays certainly a central role in alveolar clearance of inhaled NPs, including carbon NPs $[46,47]$. However, accumulation of NPs into alveolar macrophages may also lead to a release of pro-inflammatory mediators [19]. In our study, the increased quantities of interleukins (IL-6, KC) and monocyte chemoattractant protein-1 (MCP-1) in mouse BALFs are likely due to the macrophage response to CDs, leading to a lung inflammatory process. Moreover, NPs may also cause direct damage to macrophages leading to cell death in some cases [42]. Indeed, our data show a high proportion of mortality among macrophages that had taken up CDs at 4-h and 24-h post-exposure. Although in our study macrophage mortality decreased from $7 \mathrm{~d}$ post CD exposure, any weakening of 
the alveolar macrophage population would affect pulmonary clearance thereby increasing the risk of developing lung disease [19]. In order to elucidate the mechanisms involved in macrophage toxicity, we investigated next the toxicological responses evoked by our CDs in cultured macrophages.

(a)
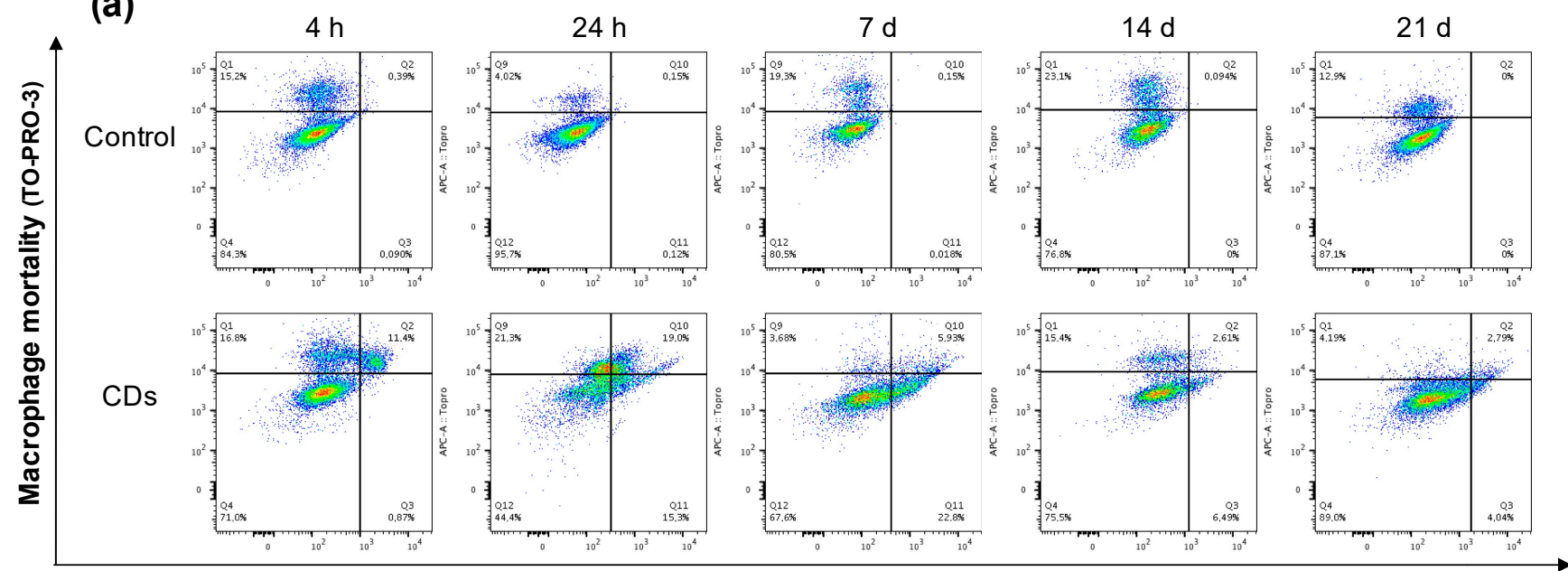

CD uptake into macrophages

(b)

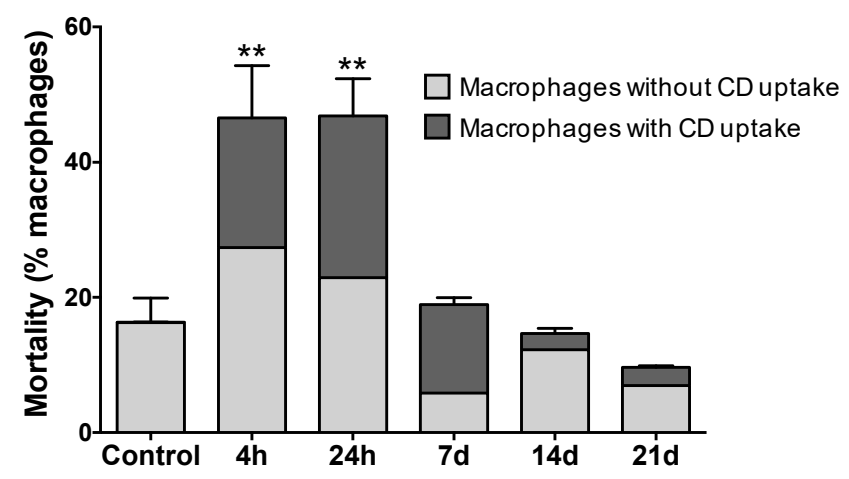

Figure 4. Alveolar macrophage mortality induced by CDs as a function of NP internalization as assessed by FACS. Mice received one administration of CDs $(100 \mu \mathrm{g})$ or saline (control), and BALFs were collected $4 \mathrm{~h}, 24 \mathrm{~h}, 7 \mathrm{~d}, 14 \mathrm{~d}$, or $21 \mathrm{~d}$ later. (a) CD-associated fluorescence (X-axis) as a function of TO-PRO-3 fluorescence (Y-axis) at the 4-h, 24-h, 7-d, 14-d, or 21-d time points (data from $\mathrm{n}=1$ mouse for each panel). (b) Kinetics of alveolar macrophage mortality in line with CD uptake. Data are means \pm SEM of $n=3$ mice. Statistical differences when compared to controls were determined by ANOVA followed by the Dunnett's test, ${ }^{* *} p<0.01$.

\subsection{Internalization of CDs by Cultured Macrophages and Its Mechanisms}

As toxicity of NPs generally involves their cell entry [48], we first investigated cell uptake of CDs by macrophages and its associated mechanisms. Following incubation of cells with non-cytotoxic concentration $(25 \mu \mathrm{g} / \mathrm{mL})$ of CDs for $4 \mathrm{~h}$, CDs were visible in the cytoplasm of macrophages as blue spots by CLSM (Figure 5a), whereas no such spots were visible in control cells. As shown on Figure 5b, a quantitative analysis conducted by FACS highlighted an increase in CD fluorescence signal into macrophages (10.9-fold compared to control, $p<0.001$ ), which confirmed CD internalization by these cells in vitro. This uptake of CDs by cultured macrophages is in agreement with our present in vivo data, and with our previous in vitro studies reporting efficient cell uptake of bPEI25k-based CDs by macrophages [36]. 
(a)

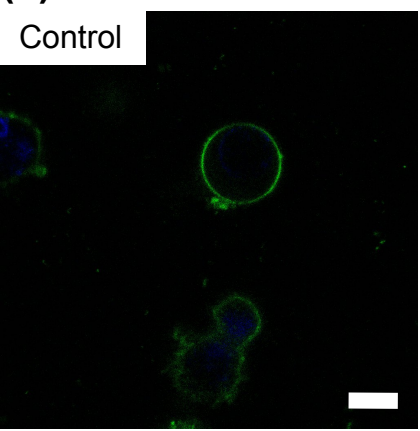

(b)

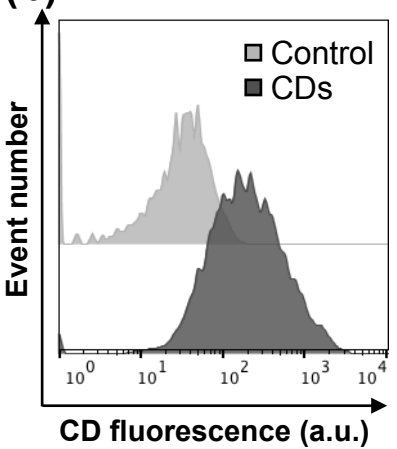

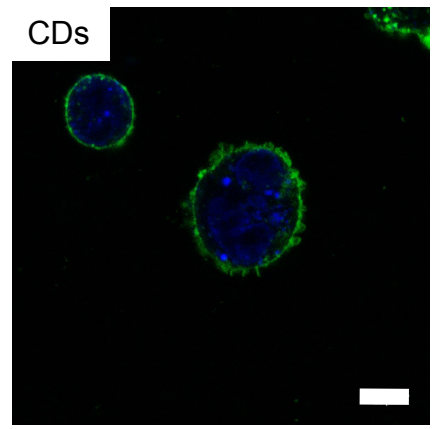

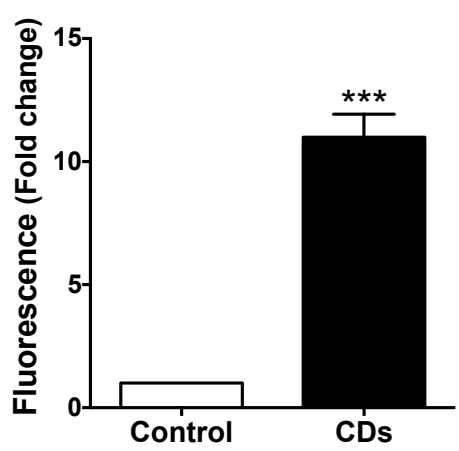

(c)

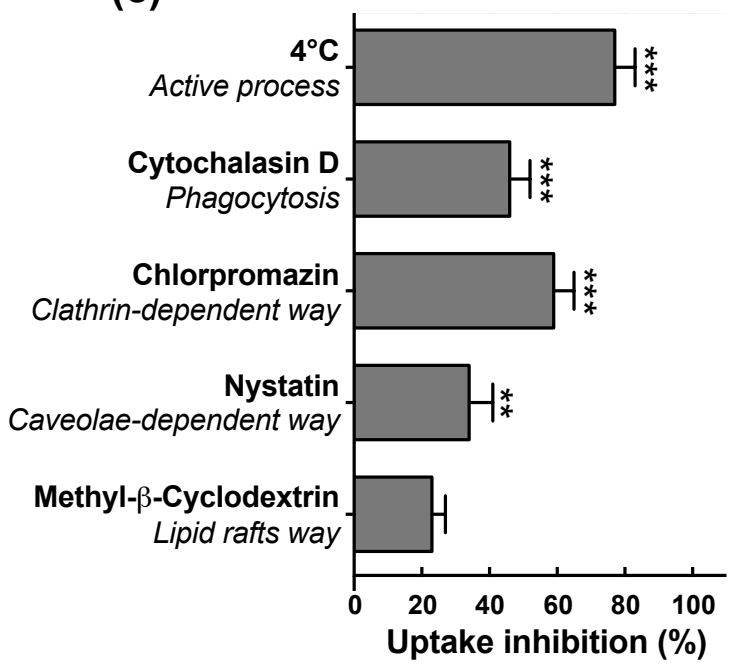

Figure 5. Uptake of CDs in cultured macrophages as assessed by CLSM or FACS. (a) CLSM analysis of unexposed cells (left) or cells exposed to $25 \mu \mathrm{g} / \mathrm{mL}$ of CDs for $4 \mathrm{~h}$ (right). Cells were stained with the fluorescent membrane probe DSQ12S before observation. Cell membrane is colored in green and CDs appear in blue (scale bar $=10 \mu \mathrm{m}$ ). (b) Quantification of CD internalization by FACS. Results are expressed as fold change in fluorescence intensity when compared to control cells and are means \pm SEM of $\mathrm{n}=9$ experiments. Statistical differences when compared to control were determined by Student's $t$-test. ${ }^{* * *} p<0.001$. (c) Study of CD internalization mechanisms by FACS. Cells were pre-incubated at $4{ }^{\circ} \mathrm{C}$ or pre-treated with various pharmacological inhibitors for $30 \mathrm{~min}$ before the addition of CDs $(25 \mu \mathrm{g} / \mathrm{mL})$. Internalization was measured at $4 \mathrm{~h}$. Results were expressed as percent of inhibition of CD uptake and are means \pm SEM of $n=3$ experiments. Statistical differences when compared to control were determined by ANOVA followed by the Dunnett's test. ${ }^{* *} p<0.01$; $* * * p<0.001$.

The different pathways involved in CD internalization were then examined by FACS (Figure 5c). Cell incubation at $4{ }^{\circ} \mathrm{C}$ (inhibition of active process) induced a reduction in CD uptake by nearly $80 \%$. This limited uptake of CDs at low temperature indicated an energy-dependent endocytosis of CDs. However, as this inhibition was not complete, a part of the CD uptake may be due to an energy-independent process, as for example passive diffusion. Such an effect could be explained by the very small size of our CDs (10 nm) and was previously reported for other CDs (1-5 nm) [49] or for other types of very small NPs as, e.g., gold NPs [50]. While methyl- $\beta$-cyclodextrin (inhibitor of lipid rafts) did not significantly alter CD cell uptake, cytochalasin D (inhibitor of phagocytosis), chlorpromazin (inhibitor of clathrin-mediated endocytosis) and nystatin (inhibitor of caveolae-mediated endocytosis) significantly inhibited the NP macrophage uptake by $46 \%, 59 \%$ and 34\%, respectively (Figure 5c). This partial inhibition of CD uptake by chlorpromazin, nystatin or cytochalasin D indicates that CD internalization is the consequence of endocytosis through at least three different pathways, clathrin- and caveolae-mediated pathways, and also phagocytosis. Widely known, clathrin- and caveolin-dependent endocytosis are two major pathways for NP cellular entry [51]. If the clathrin pathway results in the engulfment of NPs in intracellular vesicles with a size around 100-500 nm, caveolae are smaller vesicles with a diameter of 50-100 nm. So, the size of NPs determines the processes of cellular uptake [52]. In the case of ultrasmall NPs such as CDs, these two endocytosis pathways can be efficient, as it was previously reported [49]. Phagocytosis is a NP uptake mechanism 
exercised by immune cells, including macrophages. This process results from binding of NPs to cell surface receptors of phagocytes after their opsonization by serum proteins including immunoglobulins and complement proteins [51]. Our bPEI600-based CDs exhibit a positive surface charge, which could promote their interactions with negatively charged serum proteins via electrostatic bonds, thus facilitating their opsonization and therefore their phagocytosis by macrophages [53]. Finally, our results suggest that the very small size of CDs leads to their internalization by macrophages by an energy-independent process, as well as by clathrin- and caveolin-dependent endocytosis pathways. Moreover, the cationic surface of the bPEI600-based CDs may also contribute to cellular uptake by phagocytosis.

\subsection{Cellular Mechanisms Involved in the Toxicity of CDs towards Macrophages}

To evaluate the dose-dependent toxicity of CDs on cultured macrophages, cells were exposed to increasing concentrations of the NPs (3-200 $\mu \mathrm{g} / \mathrm{mL})$ for $24 \mathrm{~h}$. These concentrations were chosen according to previous works on CD toxicity $[29,33,34]$. They are in line with sets of doses recommended for nanotoxicological studies conducted on submerged cell tests [54]. Furthermore, when normalized according to the nanomaterial metric doses as proposed by Loret et al. [55], they are of the same order of magnitude as the CD doses we used in our in vivo experiments. Indeed, in our experimental conditions, the in vitro $\mathrm{CD}$ concentration of $200 \mu \mathrm{g} / \mathrm{mL}$ did correspond to a CD dose of $0.4 \mu \mathrm{g} / 10^{3}$ macrophages, whereas the in vivo $C D$ dose of $100 \mu \mathrm{g}$ was equivalent to $0.5 \mu \mathrm{g} / 10^{3}$ macrophages taking into account a number of macrophages of 250.000 in mouse airways, as determined by cell counting in BALFs of naïve animals. As shown on Figure 6a, a decrease in cell viability of $35-85 \%$ was observed at CD concentration ranging from 25 to $100 \mu \mathrm{g} / \mathrm{mL}$, and a maximum loss of viability was reached at $200 \mu \mathrm{g} / \mathrm{mL}$. Thus, in agreement with our previous studies on bPEI25k-based CDs, we found that bPEI600-based CDs are toxic to macrophages [32,36]. A lactate dehydrogenase (LDH) release was measured in the cell culture supernatants of macrophages exposed to CDs (data not shown), suggesting that the cell death induced by CDs probably occurs by a necrosis mechanism. In this type of CDs, the presence of polyamine groups at the CD surface results in a highly cationic surface of the particles, which may promote the interactions of CDs with the negatively charged cellular membranes and then their internalization, as discussed above. In addition, it was found that a positive surface charge could promote their interactions with negatively charged serum proteins via electrostatic bonds and may facilize their opsonization and therefore their phagocytosis by macrophages [53]. In the literature, other works supported this charge effect hypothesis. Indeed, Havrdova et al. showed that poly(ethyleneimine)-based CDs exhibiting positive surface charge induced greater toxicity as compared to negative or neutral ones [29]. A recent toxicogenomics study conducted in human lung fibroblasts revealed also that positive CDs induced changes of immune response and cell cycle-related processes, contrary to negative ones [56].

Next, we investigated the mechanisms leading to these viability losses using $\mathrm{CD}$ concentrations ranging from those causing little viability loss $(12 \mu \mathrm{g} / \mathrm{mL})$ to submaximal cytotoxic $(100 \mu \mathrm{g} / \mathrm{mL})$ concentrations. As the lysosome and the mitochondria are the main subcellar targets of NPs [57], we examined whether the decrease in cell viability induced by our CDs was accompanied by some disturbance of these two organelles. A significant loss in lysosomal integrity (Figure 6b) and an increase in mitochondrial dysfunction (Figure 6c) were observed in response to CDs. These effects were dose-dependent and significant from the CD concentration of $25 \mu \mathrm{g} / \mathrm{mL}$ and $50 \mu \mathrm{g} / \mathrm{mL}$ for lysosomal and mitochondrial perturbation, respectively. Induction of oxidative stress is another major mechanism of cell death evoked by NPs [20]. In order to assess the ability of CDs to induce this response, the cellular content in reduced glutathione (GSH), an anti-oxidant agent, was quantified. As shown on Figure 6d, CDs induced a dose-dependent decrease in GSH cell content reaching almost $40 \%$ at $100 \mu \mathrm{g} / \mathrm{mL}$, indicating the occurrence of oxidative stress. Next, to investigate the inflammatory effect of CDs, the levels of IL-8, which is one of the 
main macrophage-derived inflammatory cytokines, were measured in the supernatants of CD-exposed macrophages. As shown on Figure 6e, macrophage exposure to CDs resulted in a dose-dependent increase in IL-8 secretion with a significant effect from the concentration of $25 \mu \mathrm{g} / \mathrm{mL}$. Finally, the impact of CDs on NLRP3 inflammasome was evaluated by quantifying the IL-1 $\beta$ cytokine in the culture supernatants of macrophages. Indeed, NLRP3 inflammasome is a cytosolic multiprotein complex, which has a key role in the regulation of systemic and local responses to infection and injury. As illustrated on Figure $6 \mathrm{f}$, IL- $1 \beta$ was secreted by macrophages in response to CDs $(50-100 \mu \mathrm{g} / \mathrm{mL})$, highlighting that CDs can induce NLRP3 inflammasome activation.

(a)

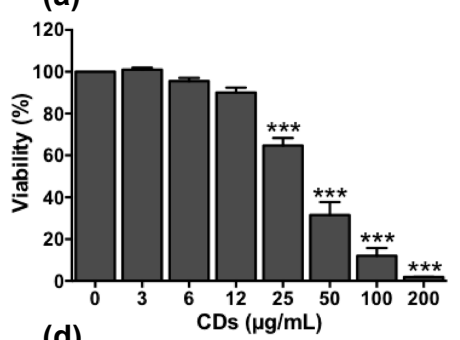

(d)

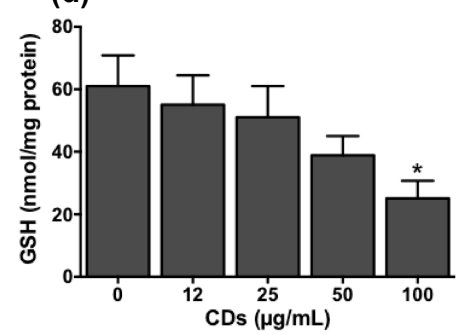

(b)

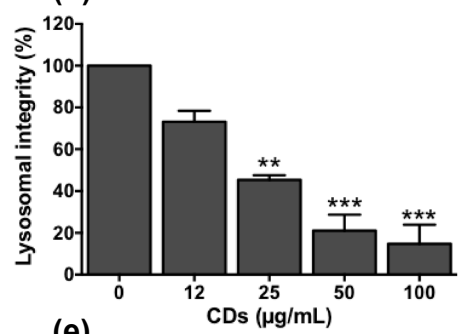

(e)

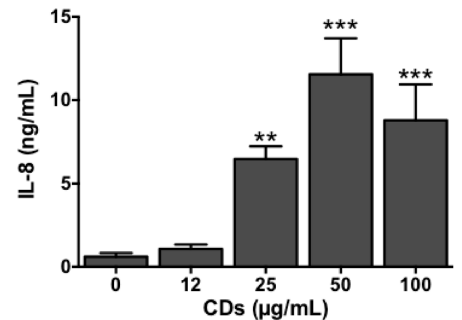

(c)

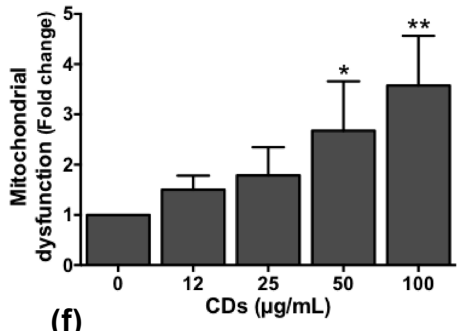

(f)

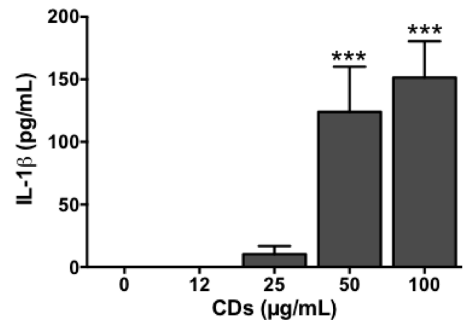

Figure 6. Cellular mechanisms involved in the toxicity of CDs towards cultured macrophages. Cells were exposed or not with increasing concentrations of CDs for $24 \mathrm{~h}(\mathbf{a}, \mathbf{b}, \mathbf{e}, \mathbf{f})$ or $4 \mathrm{~h}(\mathbf{c}, \mathbf{d})$. Cell viability (a, MTT assay), lysosomal integrity (b, neutral red assay), mitochondrial dysfunction (c, mitochondrial membrane perturbation assay), oxidative stress (d, reduced glutathione), inflammatory response (e, IL-8 secretion) and NLRP3 inflammasome activation (f, IL-1 $\beta$ secretion) were measured at $4 \mathrm{~h}(\mathbf{c}, \mathbf{d})$ or $24 \mathrm{~h}(\mathbf{a}, \mathbf{b}, \mathbf{e}, \mathbf{f})$. Data are means \pm SEM of $n=3-6$ experiments. They are expressed in percentage of controls $(\mathbf{a}, \mathbf{b})$, fold change $(\mathbf{c})$, or as absolute values $(\mathbf{d}-\mathbf{f})$. Statistical differences when compared to controls were determined by ANOVA followed by the Dunnett's test. ${ }^{*} p<0.05 ;{ }^{* *} p<0.01 ; * * * 0.001$.

We thus identified several adverse cellular effects of bPEI600-based CDs in macrophages. The first major organelle KE in response to $\mathrm{CDs}$ was disruption of the lysosome integrity. It is well known that the lysosomal membrane presents a high sensitivity to xenobiotics. Hence, lysosomal membrane integrity has already been proposed as a biomarker to evaluate potential effect of the environmental pollutants [58]. Recently, the role of lysosomal dysfunction in NP toxicity has been underlined in the literature [59]. Indeed, since endocytosis is the main way for NPs to enter cells, and since lysosomes are the terminal components of the endo/lysosomal system, most NPs end-up and accumulate in lysosomes after their cell uptake [60]. Although the exact mechanisms leading to lysosome damage are not fully understood, this trafficking to the lysosomes, associated with loss of lysosomal integrity, has been reported for NPs of various chemical composition including carbonbased NPs [61,62]. These data are also consistent with our previous work indicating that bPEI25k-based CDs were addressed to the lysosomes after their uptake by macrophages and caused a loss of lysosomal integrity [36].

A second major organelle KE induced by bPEI600-based CDs in the present study is mitochondrial dysfunction. Mitochondrial dysfunction is reported as a crucial mechanism leading to toxicity of NPs [57], including carbon-based NPs [42]. In line with our data, a recent study reported that $\mathrm{N}$-doped CDs caused a decline in mitochondrial activity in hepatocytes [33]. Mitochondrial damage in response to CDs could be a direct effect of these NPs on the organelle, as a silica nanoplatform conjugated to fluorescent CDs has 
been observed to accumulate in mitochondria in several human cell lines [63]. It is also possible that CDs affect the mitochondria by indirect pathways. Supporting this hypothesis, we previously reported that inhibition of the lysosomal protease cathepsin B significantly reduced mitochondrial dysfunction induced by bPEI25k-based CDs [36].

Another cellular KE we observed in macrophages exposed to bPEI600-based CDs is oxidative stress. Oxidative stress is undoubtedly one of most frequently reported adverse effect among all toxicity endpoints studied in the nanotoxicology literature [20,64]. Its involvement has already been mentioned in toxicity studies conducted on $\mathrm{N}$-doped CDs obtained from carbon nitride [33] or poly(ethyleneimine)-based CDs [29,36]. It has been reported that NP-induced oxidative stress may result from the production of reactive species such as ROS and/or reactive nitrogen species (RNS), or from the alteration of antioxidant activities within the cell $[20,48]$. In our study, the mitochondria dysfunction induced by CDs could result in excessive production of ROS through electron carriers from the electron transfer chain, as it has been recently reported for other types of NPs [65]. The CD-induced oxidative stress may also result from the damage to other organelles, in particular the lysosome, as described for other NPs [48].

In the present study, among the mechanisms incriminated in macrophage toxicity of bPEI600-based CDs, NLRP3 inflammasome activation also appeared as a KE, as it could participate to the inflammatory response evoked by the NPs. These last years, several kinds of NPs have been reported to activate the NLRP3 inflammasome, and nanoparticleassociated molecular patterns (NAMPs) have been proposed to be new danger signals leading to NLRP3 inflammasome activation [66]. Among possible NLRP3 activation mechanisms, ROS production [67] or destabilization of lysosomes and release of cathepsin B into macrophage cytoplasm have been proposed in the case of carbon-based nanomaterials [68], including CDs [36].

\section{Conclusions}

In this study, the combination of in vivo and in vitro experimental approaches was used to propose an AOP related to the acute lung injury induced by polyamine-based cationic CDs (Figure 7). Based on our data, we propose that uptake of CDs by macrophages constitutes the MIE of this pathway, followed by the loss of lysosomal integrity, mitochondrial disruption, oxidative stress, and inflammasome activation as KEs. All these effects may trigger macrophage death, leading to lung inflammation. This putative AOP is aligned with the recommended KEs that emerged from the network of inflammation-related AOPs [69]. Besides, as lung inflammation may lead to acute lung injury, lung fibrosis or lung cancer, it could be extended and/or connected to other larger networks in the field of inhalation toxicology in the AOP-Wiki database. Although each NP exhibits specific physicochemical properties, such as size and surface charge or chemistry that govern their interactions with biological environment and influence their toxicity potential [70], the AOP we propose could be useful for providing clarity on lung toxicity mechanisms for other types of NPs than CDs, especially other cationic NPs. In addition, some KEs described in this study such as oxidative stress or inflammation are described in AOPs under development for lung toxicity induced by chemicals [71]. But our data highlight some major differences between the toxicodynamics of chemical compounds and NPs. These differences lie in particular within the MIE (cell uptake of NPs) and the early KE (lysosomal dysfunction induced by NPs). Thus, in our opinion, the integration of specific KEs related to nanomaterials inside pre-existing AOPs, and also the development of AOPs specific to nanomaterials should be encouraged in order to provide new insights to gain a better understanding of NP toxicity. This is valuable for identifying endpoints and targeted biomarkers for nanosafety assessment. 
Adverse outcome pathway (AOP) for acute lung inflammation induced by carbon dot nanoparticles

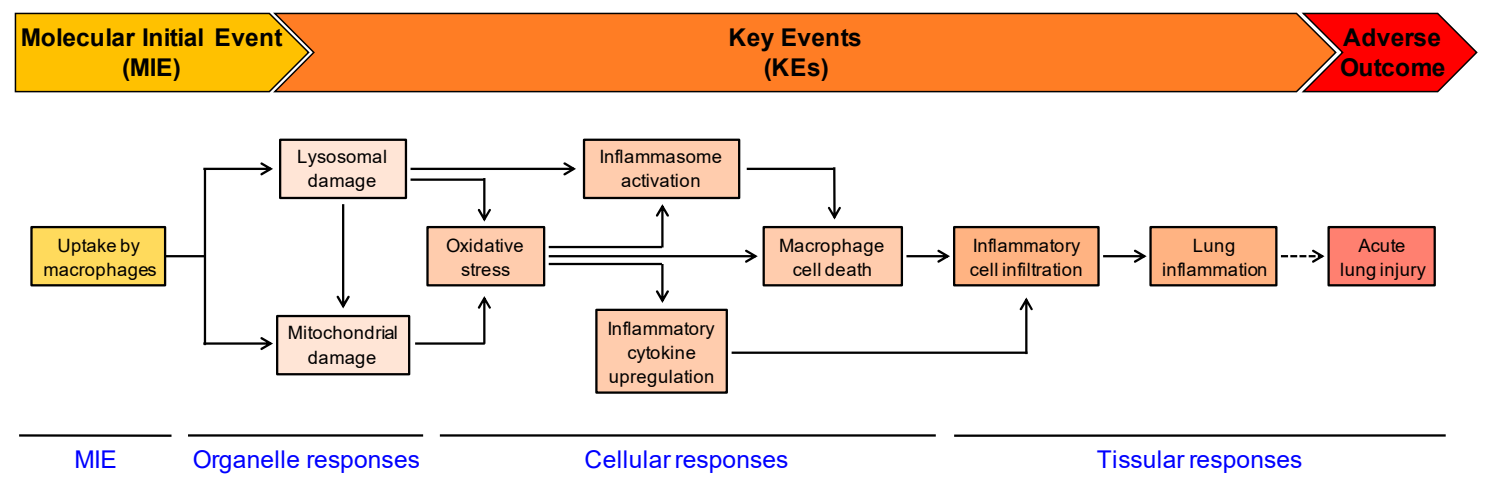

Figure 7. Putative AOP related to the acute lung inflammation induced by polyamine-based cationic CDs. The uptake of CDs by macrophages constitutes the MIE, followed by the KEs, which are the loss of lysosomal integrity and mitochondrial disruption (organelle responses), oxidative stress, inflammasome activation, inflammatory cytokine upregulation and macrophage death (cellular responses). All these effects may trigger inflammatory cell infiltration, leading to lung inflammation (tissular responses).

Author Contributions: M.W. performed the experiments and analyzed the data. J.F. performed the experiments. M.C. performed the synthesis of CDs. L.L. supervised the study and revised the manuscript. F.P. supervised the study and revised the manuscript. C.R. analyzed the data, supervised the study and wrote the paper. All authors have read and agreed to the published version of the manuscript.

Funding: This work was supported by the Agence Nationale de Sécurité Sanitaire de l'alimentation, de l'environnement et du travail (ANSES-Grant number: EST-2015/1/005) and the Agence Nationale de la Recherche (ANR-Grant number: ANR-18-CE34-0005-01).

Institutional Review Board Statement: Animal experiments were conducted in compliance with the European legislation (Directive 2010/63/EU). Experimental protocols were approved by the local ethics committee (CREMEAS, agreement number \#4674).

Informed Consent Statement: Not applicable.

Data Availability Statement: Data presented in this study are available by requesting from the corresponding author.

Acknowledgments: The authors thank Pascal Didier for its help with CLSM (Laboratoire de Bioimagerie et Pathologies, UMR 7021, Faculté de Pharmacie, CNRS-Université de Strasbourg, Illkirch, France), as well as Claudine Ebel and Muriel Koch for their help with FACS experiments (Cytometry platform, IGBMC, Strasbourg).

Conflicts of Interest: The authors declare no conflict of interest. The funders had no role in the design of the study; in the collection, analyses, or interpretation of data; in the writing of the manuscript, or in the decision to publish the results.

\section{References}

1. Vance, M.E.; Kuiken, T.; Vejerano, E.P.; McGinnis, S.P.; Hochella, M.F., Jr.; Rejeski, D.; Hull, M.S. Nanotechnology in the real world: Redeveloping the nanomaterial consumer products inventory. Beilstein J. Nanotechnol. 2015, 6, 1769-1780. [CrossRef] [PubMed]

2. Xu, X.Y.; Ray, R.; Gu, Y.L.; Ploehn, H.J.; Gearheart, L.; Raker, K.; Scrivens, W.A. Electrophoretic analysis and purification of fluorescent single-walled carbon nanotube fragments. J. Am. Chem. Soc. 2004, 126, 12736-12737. [CrossRef] [PubMed]

3. Himaja, A.L.; Karthik, P.S.; Singh, S.P. Carbon Dots: The newest member of the carbon nanomaterials family. Chem. Rec. 2015, 15, 595-615. [CrossRef]

4. Kang, C.; Huang, Y.; Yang, H.; Yan, X.F.; Chen, Z.P. A review of carbon dots produced from biomass wastes. Nanomaterials 2020, 10, 2316. [CrossRef] [PubMed]

5. Claudel, M.; Fan, J.H.; Rapp, M.; Pons, F.; Lebeau, L. Influence of carbonization conditions on luminescence and gene delivery properties of nitrogen-doped carbon dots. RSC Adv. 2019, 9, 3493-3502. [CrossRef] 
6. Huang, D.P.; Zhou, H.F.; Wu, Y.Q.; Wang, T.; Sun, L.L.; Gao, P.; Sun, Y.Z.; Huang, H.N.; Zhou, G.J.; Hu, J.F. Bottom-up synthesis and structural design strategy for graphene quantum dots with tunable emission to the near infrared region. Carbon 2019, 142, 673-684. [CrossRef]

7. Kang, Z.H.; Lee, S.T. Carbon dots: Advances in nanocarbon applications. Nanoscale 2019, 11, 19214-19224. [CrossRef]

8. Ghosal, K.; Ghosh, A. Carbon dots: The next generation platform for biomedical applications. Mater. Sci. Eng. C 2019, 96, 887-903. [CrossRef]

9. Du, J.J.; Xu, N.; Fan, J.L.; Sun, W.; Peng, X.J. Carbon dots for in vivo bioimaging and theranostics. Small 2019, 15 , e1805087. [CrossRef]

10. Gomez, I.J.; Arnaiz, B.; Cacioppo, M.; Arcudi, F.; Prato, M. Nitrogen-doped carbon nanodots for bioimaging and delivery of paclitaxel. J. Mater. Chem. B. 2018, 6, 5540-5548. [CrossRef]

11. Yuan, Y.; Guo, B.; Hao, L.; Liu, N.; Lin, Y.; Guo, W.; Li, X.; Gu, B. Doxorubicin-loaded environmentally friendly carbon dots as a novel drug delivery system for nucleus targeted cancer therapy. Colloid Surf. B Biointerfaces 2017, 159, 349-359. [CrossRef] [PubMed]

12. Kim, S.; Choi, Y.; Park, G.; Won, C.; Park, Y.J.; Lee, Y.; Kim, B.S.; Min, D.H. Highly efficient gene silencing and bioimaging based on fluorescent carbon dots in vitro and in vivo. Nano Res. 2017, 10, 503-519. [CrossRef]

13. Pierrat, P.; Wang, R.; Kereselidze, D.; Lux, M.; Didier, P.; Kichler, A.; Pons, F.; Lebeau, L. Efficient in vitro and in vivo pulmonary delivery of nucleic acid by carbon dot-based nanocarriers. Biomaterials 2015, 51, 290-302. [CrossRef] [PubMed]

14. Hassan, M.; Gomes, V.G.; Dehghani, A.; Ardekani, S.M. Engineering carbon quantum dots for photomediated theranostics. Nano Res. 2018, 11, 1-41.

15. Nel, A.; Xia, T.; Madler, L.; Li, N. Toxic potential of materials at the nanolevel. Science 2006, 311, 622-627. [CrossRef]

16. Oberdorster, G.; Oberdorster, E.; Oberdorster, J. Nanotoxicology: An emerging discipline evolving from studies of ultrafine particles. Environ. Health Perspect. 2005, 113, 823-839. [CrossRef] [PubMed]

17. Kreyling, W.G.; Semmler-Behnke, M.; Takenaka, S.; Moller, W. Differences in the biokinetics of inhaled nano- versus micrometersized particles. Acc. Chem. Res. 2013, 46, 714-722. [CrossRef] [PubMed]

18. Ronzani, C.; Spiegelhalter, C.; Vonesch, J.L.; Lebeau, L.; Pons, F. Lung deposition and toxicological responses evoked by multiwalled carbon nanotubes dispersed in a synthetic lung surfactant in the mouse. Arch. Toxicol. 2012, 86, 137-149. [CrossRef] [PubMed]

19. Laskin, D.L.; Malaviya, R.; Laskin, J.D. Role of macrophages in acute lung injury and chronic fibrosis induced by pulmonary toxicants. Toxicol. Sci. 2019, 168, 287-301. [CrossRef]

20. Manke, A.; Wang, L.Y.; Rojanasakul, Y. Mechanisms of nanoparticle-induced oxidative stress and toxicity. Biomed. Res. Int. 2013, 2013, 942916. [CrossRef]

21. Nho, R. Pathological effects of nano-sized particles on the respiratory system. Nanomed. Nanotechnol. 2020, 29, 102242. [CrossRef]

22. Krug, H.F.; Wick, P. Nanotoxicology: An interdisciplinary challenge. Angew. Chem. Int. Ed. 2011, 50, 1260-1278. [CrossRef] [PubMed]

23. Gerloff, K.; Landesmann, B.; Worth, A.; Munn, S.; Palosaari, T.; Whelan, M. The adverse outcome pathway approach in nanotoxicology. Comput. Toxicol. 2017, 1,3-11. [CrossRef]

24. Ankley, G.T.; Edwards, S.W. The Adverse Outcome Pathway: A multifaceted framework supporting 21st century toxicology. Curr. Opin. Toxicol. 2018, 9, 1-7. [CrossRef] [PubMed]

25. Hecker, M.; LaLone, C.A. Adverse Outcome Pathways: Moving from a scientific concept to an internationally accepted framework. Environ. Toxicol. Chem. 2019, 38, 1152-1163. [CrossRef]

26. Halappanavar, S.; van den Brule, S.; Nymark, P.; Gate, L.; Seidel, C.; Valentino, S.; Zhernovkov, V.; Danielsen, P.H.; De Vizcaya, A.; Wolff, H.; et al. Adverse outcome pathways as a tool for the design of testing strategies to support the safety assessment of emerging advanced materials at the nanoscale. Part. Fibre Toxicol. 2020, 17, 16. [CrossRef]

27. Vietti, G.; Lison, D.; van den Brule, S. Mechanisms of lung fibrosis induced by carbon nanotubes: Towards an Adverse Outcome Pathway (AOP). Part. Fibre Toxicol. 2016, 13, 11. [CrossRef]

28. Labib, S.; Williams, A.; Yauk, C.L.; Nikota, J.K.; Wallin, H.; Vogel, U.; Halappanavar, S. Nano-risk Science: Application of toxicogenomics in an adverse outcome pathway framework for risk assessment of multi-walled carbon nanotubes. Part. Fibre Toxicol. 2016, 13, 15. [CrossRef]

29. Havrdova, M.; Hola, K.; Skopalik, J.; Tomankova, K.; Martin, P.A.; Cepe, K.; Polakova, K.; Tucek, J.; Bourlinos, A.B.; Zboril, R. Toxicity of carbon dots-Effect of surface functionalization on the cell viability, reactive oxygen species generation and cell cycle. Carbon 2016, 99, 238-248. [CrossRef]

30. Liu, C.J.; Zhang, P.; Zhai, X.Y.; Tian, F.; Li, W.C.; Yang, J.H.; Liu, Y.; Wang, H.B.; Wang, W.; Liu, W.G. Nano-carrier for gene delivery and bioimaging based on carbon dots with PEI-passivation enhanced fluorescence. Biomaterials 2012, 33, 3604-3613. [CrossRef]

31. Yang, Y.; Ren, X.L.; Sun, Z.N.; Fu, C.H.; Liu, T.L.; Meng, X.W.; Wang, Z.L. Toxicity and bio-distribution of carbon dots after single inhalation exposure in vivo. Chin. Chem. Lett. 2018, 29, 895-898. [CrossRef]

32. Fan, J.H.; Claudel, M.; Ronzani, C.; Arezki, Y.; Lebeau, L.; Pons, F. Physicochemical characteristics that affect carbon dot safety: Lessons from a comprehensive study on a nanoparticle library. Int. J. Pharm. 2019, 569, 118521. [CrossRef] [PubMed]

33. Zhang, T.; Qu, J.; Yao, Y.; Zhang, Y.; Ma, Y.; Wu, D.; Cao, Y.; Yang, M.; Zhang, Y.; Tang, M.; et al. N-doped carbon dots triggered the induction of ROS-mediated cytoprotective autophagy in Hepa1-6 cells. Chemosphere 2020, 251, 126440. [CrossRef] [PubMed] 
34. Lategan, K.; Fowler, J.; Bayati, M.; de Cortalezzi, M.F.; Pool, E. The effects of carbon dots on immune system biomarkers, using the murine macrophage cell line RAW 264.7 and human whole blood cell cultures. Nanomaterials 2018, 8, 388. [CrossRef] [PubMed]

35. Chen, J.T.; Sun, H.Q.; Ruan, S.B.; Wang, Y.; Shen, S.; Xu, W.M.; He, Q.; Gao, H.L. In vitro and in vivo toxicology of bare and PEGylated fluorescent carbonaceous nanodots in mice and zebrafish: The potential relationship with autophagy. RSC Adv. 2015, 5, 38547-38557. [CrossRef]

36. Ronzani, C.; Van Belle, C.; Didier, P.; Spiegelhalter, C.; Pierrat, P.; Lebeau, L.; Pons, F. Lysosome mediates toxicological effects of polyethyleneimine-based cationic carbon dots. J. Nanopart. Res. 2019, 21, 4. [CrossRef]

37. Ronzani, C.; Casset, A.; Pons, F. Exposure to multi-walled carbon nanotubes results in aggravation of airway inflammation and remodeling and in increased production of epithelium-derived innate cytokines in a mouse model of asthma. Arch. Toxicol. 2014, 88, 489-499. [CrossRef]

38. Daubeuf, F.; Becker, J.; Aguilar-Pimentel, J.A.; Ebel, C.; Hrabe de Angelis, M.; Herault, Y.; Frossard, N. A fast, easy, and customizable eight-color flow cytometric method for analysis of the cellular content of bronchoalveolar lavage fluid in the mouse. Curr. Protoc. Mouse Biol. 2017, 7, 88-99. [CrossRef]

39. Jhingran, A.; Kasahara, S.; Hohl, T.M. Flow cytometry of lung and bronchoalveolar lavage fluid cells from mice challenged with fluorescent Aspergillus Reporter (FLARE) Conidia. Bio Protoc. 2016, 6, e1927. [CrossRef]

40. Collot, M.; Kreder, R.; Tatarets, A.L.; Patsenker, L.D.; Mely, Y.; Klymchenko, A.S. Bright fluorogenic squaraines with tuned cell entry for selective imaging of plasma membrane vs. endoplasmic reticulum. Chem. Commun. 2015, 51, 17136-17139. [CrossRef]

41. Safar, R.; Ronzani, C.; Diab, R.; Chevrier, J.; Bensoussan, D.; Grandemange, S.; Le Faou, A.; Rihn, B.H.; Joubert, O. Human monocyte response to S-nitrosoglutathione-loaded nanoparticles: Uptake, viability, and transcriptome. Mol. Pharm. 2015, 12, 554-561. [CrossRef] [PubMed]

42. Yuan, X.; Nie, W.; He, Z.; Yang, J.; Shao, B.; Ma, X.; Zhang, X.; Bi, Z.; Sun, L.; Liang, X.; et al. Carbon black nanoparticles induce cell necrosis through lysosomal membrane permeabilization and cause subsequent inflammatory response. Theranostics 2020, 10, 4589-4605. [CrossRef] [PubMed]

43. Zhou, L.X.; Li, P.Y.; Zhang, M.Y.; Han, B.; Chu, C.; Su, X.; Li, B.H.; Kang, H.; Ning, J.; Zhang, B.Y.; et al. Carbon black nanoparticles induce pulmonary fibrosis through NLRP3 inflammasome pathway modulated by miR-96 targeted FOXO3a. Chemosphere 2020, 241, 125075. [CrossRef] [PubMed]

44. Wiemann, M.; Vennemann, A.; Sauer, U.G.; Wiench, K.; Ma-Hock, L.; Landsiedel, R. An in vitro alveolar macrophage assay for predicting the short-term inhalation toxicity of nanomaterials. J. Nanobiotechnol. 2016, 14, 16. [CrossRef] [PubMed]

45. Joshi, N.; Walter, J.M.; Misharin, A.V. Alveolar macrophages. Cell Immunol. 2018, 330, 86-90. [CrossRef] [PubMed]

46. Elgrabli, D.; Dachraoui, W.; Menard-Moyon, C.; Liu, X.J.; Begin, D.; Begin-Colin, S.; Bianco, A.; Gazeau, F.; Alloyeau, D. Carbon nanotube degradation in macrophages: Live nanoscale monitoring and understanding of biological pathway. ACS Nano 2015, 9 , 10113-10124. [CrossRef]

47. Elgrabli, D.; Floriani, M.; Abella-Gallart, S.; Meunier, L.; Gamez, C.; Delalain, P.; Rogerieux, F.; Boczkowski, J.; Lacroix, G. Biodistribution and clearance of instilled carbon nanotubes in rat lung. Part. Fibre Toxicol. 2008, 5, 20. [CrossRef]

48. Marano, F.; Hussain, S.; Rodrigues-Lima, F.; Baeza-Squiban, A.; Boland, S. Nanoparticles: Molecular targets and cell signalling. Arch. Toxicol. 2011, 85, 733-741. [CrossRef]

49. Zhou, N.; Zhu, S.J.; Maharjan, S.; Hao, Z.Y.; Song, Y.B.; Zhao, X.H.; Jiang, Y.F.; Yang, B.; Lu, L.J. Elucidating the endocytosis, intracellular trafficking, and exocytosis of carbon dots in neural cells. RSC Adv. 2014, 4, 62086-62095. [CrossRef]

50. Lund, T.; Callaghan, M.F.; Williams, P.; Turmaine, M.; Bachmann, C.; Rademacher, T.; Roitt, I.M.; Bayford, R. The influence of ligand organization on the rate of uptake of gold nanoparticles by colorectal cancer cells. Biomaterials 2011, 32, 9776-9784. [CrossRef]

51. Donahue, N.D.; Acar, H.; Wilhelm, S. Concepts of nanoparticle cellular uptake, intracellular trafficking, and kinetics in nanomedicine. Adv. Drug Deliv. Rev. 2019, 143, 68-96. [CrossRef] [PubMed]

52. Zhang, S.L.; Gao, H.J.; Bao, G. Physical principles of nanoparticle cellular endocytosis. ACS Nano 2015, 9, 8655-8671. [CrossRef] [PubMed]

53. Mahmoudi, M.; Lynch, I.; Ejtehadi, M.R.; Monopoli, M.P.; Bombelli, F.B.; Laurent, S. Protein-nanoparticle interactions: Opportunities and challenges. Chem. Rev. 2011, 111, 5610-5637. [CrossRef] [PubMed]

54. Drasler, B.; Sayre, P.; Steinhauser, K.G.; Petri-Fink, A.; Rothen-Rutishauser, B. In vitro approaches to assess the hazard of nanomaterials. Nanoimpact 2017, 8, 99-116. [CrossRef]

55. Loret, T.; Rogerieux, F.; Trouiller, B.; Braun, A.; Egles, C.; Lacroix, G. Predicting the in vivo pulmonary toxicity induced by acute exposure to poorly soluble nanomaterials by using advanced in vitro methods. Part. Fibre Toxicol. 2018, 15, 25. [CrossRef]

56. Sima, M.; Vrbova, K.; Zavodna, T.; Honkova, K.; Chvojkova, I.; Ambroz, A.; Klema, J.; Rossnerova, A.; Polakova, K.; Malina, T.; et al. The differential effect of carbon dots on gene expression and DNA methylation of human embryonic lung fibroblasts as a function of surface charge and dose. Int. J. Mol. Sci. 2020, 21, 4763. [CrossRef]

57. Liu, N.; Tang, M. Toxic effects and involved molecular pathways of nanoparticles on cells and subcellular organelles. J. Appl. Toxicol. 2020, 40, 16-36. [CrossRef]

58. Moore, M.N.; Allen, J.I.; McVeigh, A. Environmental prognostics: An integrated model supporting lysosomal stress responses as predictive biomarkers of animal health status. Mar. Environ. Res. 2006, 61, 278-304. [CrossRef] 
59. Stern, S.T.; Adiseshaiah, P.P.; Crist, R.M. Autophagy and lysosomal dysfunction as emerging mechanisms of nanomaterial toxicity. Part. Fibre Toxicol. 2012, 9, 20. [CrossRef]

60. Zhao, F.; Zhao, Y.; Liu, Y.; Chang, X.; Chen, C.; Zhao, Y. Cellular uptake, intracellular trafficking, and cytotoxicity of nanomaterials. Small 2011, 7, 1322-1337. [CrossRef]

61. Tahara, Y.; Nakamura, M.; Yang, M.; Zhang, M.; Iijima, S.; Yudasaka, M. Lysosomal membrane destabilization induced by high accumulation of single-walled carbon nanohorns in murine macrophage RAW 264.7. Biomaterials 2012, 33, 2762-2769. [CrossRef] [PubMed]

62. Wan, B.; Wang, Z.X.; Lv, Q.Y.; Dong, P.X.; Zhao, L.X.; Yang, Y.; Guo, L.H. Single-walled carbon nanotubes and graphene oxides induce autophagosome accumulation and lysosome impairment in primarily cultured murine peritoneal macrophages. Toxicol. Lett. 2013, 221, 118-127. [CrossRef]

63. Zhang, Y.; Shen, Y.J.; Teng, X.Y.; Yan, M.Q.; Bi, H.; Morais, P.C. Mitochondria-targeting nanoplatform with fluorescent carbon dots for long time imaging and magnetic field-enhanced cellular uptake. ACS Appl. Mater. Interfaces 2015, 7, 10201-10212. [CrossRef] [PubMed]

64. Li, N.; Xia, T.; Nel, A.E. The role of oxidative stress in ambient particulate matter-induced lung diseases and its implications in the toxicity of engineered nanoparticles. Free Radic. Biol. Med. 2008, 44, 1689-1699. [CrossRef] [PubMed]

65. Hu, M.; Palic, D. Micro- and nano-plastics activation of oxidative and inflammatory adverse outcome pathways. Redox Biol. 2020, 37, 101620. [CrossRef]

66. Shirasuna, K.; Karasawa, T.; Takahashi, M. Exogenous nanoparticles and endogenous crystalline molecules as danger signals for the NLRP3 inflammasomes. J. Cell Physiol. 2019, 234, 5436-5450. [CrossRef]

67. Abais, J.M.; Xia, M.; Zhang, Y.; Boini, K.M.; Li, P.L. Redox regulation of NLRP3 inflammasomes: ROS as trigger or effector? Antioxid. Redox Signal 2015, 22, 1111-1129. [CrossRef]

68. Svadlakova, T.; Hubatka, F.; Knotigova, P.T.; Kulich, P.; Masek, J.; Kotoucek, J.; Macak, J.; Motola, M.; Kalbac, M.; Kolackova, M.; et al. Proinflammatory effect of carbon-based nanomaterials: In vitro study on stimulation of inflammasome NLRP3 via destabilisation of lysosomes. Nanomaterials 2020, 10, 418. [CrossRef]

69. Villeneuve, D.L.; Landesmann, B.; Allavena, P.; Ashley, N.; Bal-Price, A.; Corsini, E.; Halappanavar, S.; Hussell, T.; Laskin, D.; Lawrence, T.; et al. Representing the process of inflammation as Key Events in Adverse Outcome Pathways. Toxicol. Sci. 2018, 163, 346-352. [CrossRef]

70. Braakhuis, H.M.; Park, M.V.D.Z.; Gosens, I.; De Jong, W.H.; Cassee, F.R. Physicochemical characteristics of nanomaterials that affect pulmonary inflammation. Part. Fibre Toxicol. 2014, 11, 18. [CrossRef]

71. Clippinger, A.J.; Allen, D.; Behrsing, H.; BeruBe, K.A.; Bolger, M.B.; Casey, W.; DeLorme, M.; Gaca, M.; Gehen, S.C.; Glover, K.; et al. Pathway-based predictive approaches for non-animal assessment of acute inhalation toxicity. Toxicol. In Vitro 2018, 52, 131-145. [CrossRef] [PubMed] 